\title{
Moult - La Hoguette
}

$n^{\circ} 3440$

\section{Pierre Giraud}

\section{(2) OpenEdition \\ Journals}

Édition électronique

URL : http://journals.openedition.org/adlfi/16991

ISSN : 2114-0502

Éditeur

Ministère de la culture

Référence électronique

Pierre Giraud, « Moult - La Hoguette », ADLFI. Archéologie de la France - Informations [En ligne], BasseNormandie, mis en ligne le 16 mars 2016, consulté le 02 mai 2019. URL : http:// journals.openedition.org/adlfi/16991

Ce document a été généré automatiquement le 2 mai 2019.

(C) Ministère de la Culture et de la Communication, CNRS 


\title{
Moult - La Hoguette
}

$\mathrm{n}^{\circ} 3440$

\author{
Pierre Giraud
}

Lien Atlas (MCC) :

http://atlas.patrimoines.culture.fr/atlas/trunk/index.php?

ap_theme=DOM_2.01.02\&ap_bbox=-0.205;49.095;-0.125;49.131

1 Dans le cadre d'un projet d'agrandissement d'un réservoir d'eau potable, d'une superficie de $1230 \mathrm{~m}^{2}$, un diagnostic a été réalisé sur le site fortifié de la Hoguette à Moult. Les structures archéologiques mises au jour offrent une forte densité dans les trois sondages, avec trente-six faits repérés. Deux périodes d'occupation ont pu être identifiées.

2 La première appartient au Néolithique moyen II (apparentée à la culture Chasséenne ?). Elle est identifiée principalement par la présence d'une fosse comprenant un abondant mobilier de cette période. Cette excavation contient des rejets domestiques (céramique, matériel lithique), qui témoignent de la présence d'habitations. Il est probable qu'une partie des trous de poteau localisés dans chacune des tranchées du diagnostic est attribuable à cette implantation préhistorique. Tranchée 2 , un alignement de trois trous de poteau pourrait correspondre à un bâtiment d'orientation nord-sud. Les exemples d'occupation de sites de hauteur au Néolithique moyen II sont assez fréquents; c'est le cas sur celui de Banville, la Burette, dans le Calvados. Sur ce site, des fouilles programmées menées par Gwenolé Kerdivel ont révélé de nombreuses structures domestiques, dont un grand bâtiment rectangulaire sur tranchées.

3 La seconde occupation est à mettre en relation avec le système défensif de l'éperon attribué à la fin de La Tène finale (vers le milieu du $\mathrm{I}^{\mathrm{er}} \mathrm{s}$. av. J.-C.), dont le talus massif est conservé sur plus de $4 \mathrm{~m}$ de hauteur. Ce dernier a été sondé par Hervé Duval en juillet 2013 (opération d'archéologie programmée). Une chaussée à fossés bordiers aménagée avec des galets, conservée au niveau de la tranchée 3 , semble se prolonger vers l'ouest (tranchée 2). Plusieurs structures linéaires (fossés et/ou tranchées de palissades), parallèles au rempart, pourraient délimiter différents espaces. Dans un secteur délimité 
par une structure linéaire, qui a subi plusieurs réfections et par le talus dit « de barrage ", un probable bâtiment sur tranchée avec radier de sol est particulièrement bien conservé. La facture de ce bâtiment rappelle celle de bâtiments découverts dans un quartier localisé contre le rempart de l'oppidum principal des lexoviens à Saint-Désir-de Lisieux.

L'échantillonnage de quelques structures a permis d'exhumer un mobilier assez varié comprenant des céramiques d'importation que sont les amphores vinaires italiques républicaines. Les fragments de poterie mises au jour sont issues de productions comparables à celles provenant de sites du Pays d'Auge de La Tène D2.

5 Ces sondages ont permis d'entrevoir l'organisation spatiale assez élaborée de ce site fortifié de La Tène finale; elle rappelle notamment par la présence d'une chaussée de contour celle du site de Commes, le Mont Cavalier. La fonction de ces sites fortifiés de hauteur de petites dimensions (moins de 5 hectares) reste mal documentée. La proximité d'un axe de circulation important, peut-être au niveau d'une frontière entre deux cités, pourrait justifier le choix de son implantation.

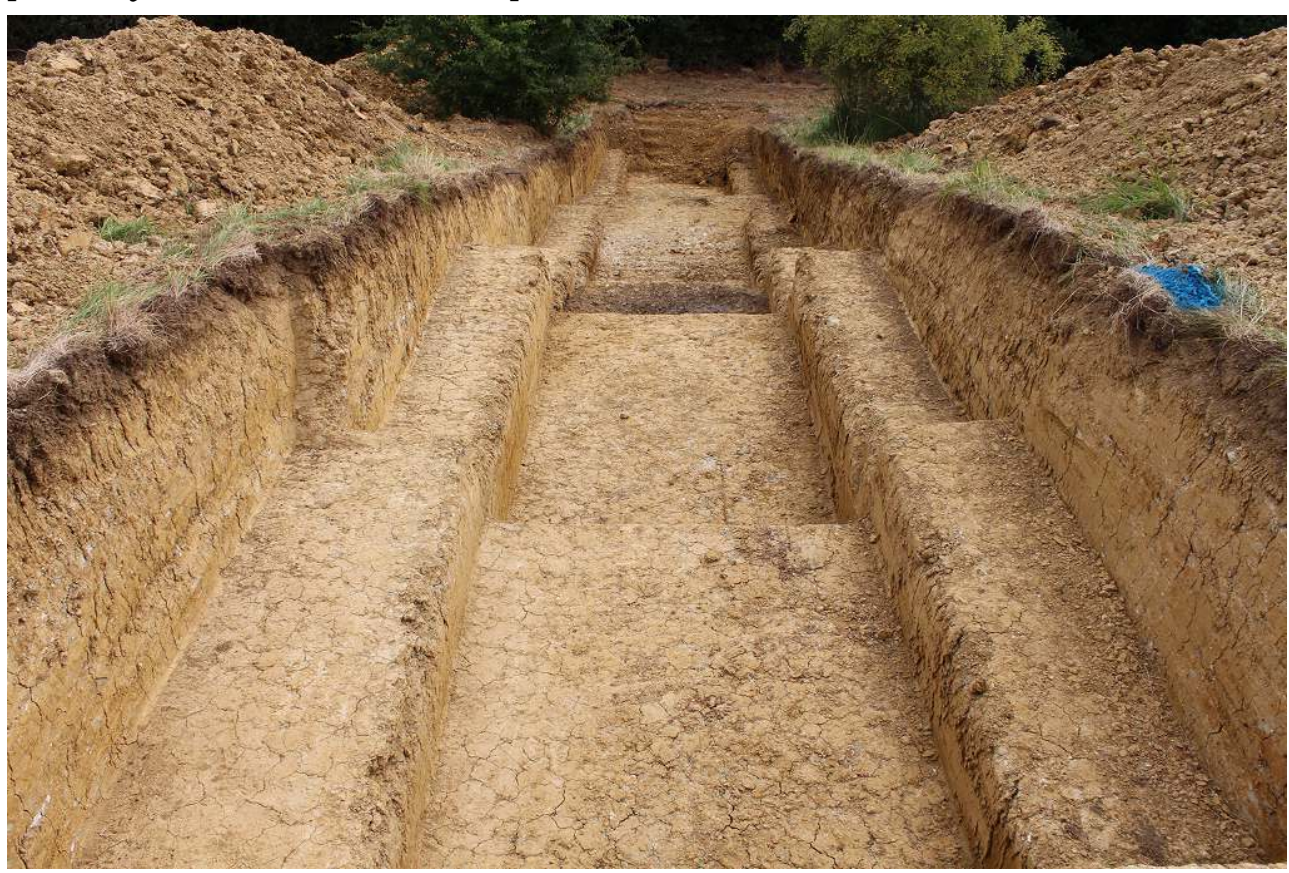

Fig 01

Sondage dans le rempart

Cliché : CG 14 
INDEX

Index chronologique : Néolithique, âge du Fer

Mots-clés : site fortifié, fosse, voie, bâtiment, amphore

operation Diagnostic (EV)

Index géographique : Basse-Normandie, Calvados (14), Moult

\section{AUTEURS}

\section{PIERRE GIRAUD}

CG 14 